\title{
El Análisis Dinámico de Redes Sociales con SIENA. Método, Discusión y Aplicación ${ }^{1}$
}

\author{
AinhoA de FEDERICO de la RÚA \\ Université des Sciences et Technologies de Lille \\ federico@univ-lille1.fr
}

Recepción: septiembre 2005

Aceptación: noviembre 2005

\section{ANALIZAR LA ESTRUCTURA DE UNA RED}

Clyde Mitchel (1969) define una red como «un conjunto particular de interrelaciones (linkeages) entre un conjunto limitado de personas, con la propiedad adicional de que las características de estas interrelaciones, consideradas como una totalidad, pueden ser utilizadas para interpretar el comportamiento social de las personas implicadas». Esta cita muestra con acierto la perspectiva dominante de los investigadores que analizan las redes sociales: las características de una red son examinadas como variables explicativas del comportamiento social (conductas, opiniones, estrategias...) de las personas implicadas en ellas. Las posiciones ocupadas por los actores de la red son puestas de manifiesto como factores explicativos cruciales de sus oportunidades, constricciones y márgenes de maniobra para la acción. En este caso la red social es utilizada como una variable contextual particularmente sofisticada que no necesita ser explicada en si misma.

Una segunda perspectiva, más tardía en el análisis de redes sociales, centra su atención en las propias relaciones y en explicar su emergencia, su organización, sus interdependencias, sus evoluciones... En esta perspectiva, las redes sociales deben ser explicadas a partir del comportamiento social (conductas, opiniones, estrategias...) de los actores implicados en ellas. Este artículo participa de esta segunda perspectiva. Se expondrán aquí herramientas metodológicas, en particular el modelo estadístico SIENA, que han sido desarrolladas para explicar las estructuras de las redes sociales.

Analizar los factores que intervienen en el establecimiento de relaciones en un conjunto de actores (una red total) es una tarea compleja que requiere el desarrollo de modelos estadísticos específicos. La particularidad y la dificultad de los modelos para redes sociales es que éstos deben representar la dependencia

1 Este artículo es una versión actualizada de Federico (2004). 
estadística entre observaciones (lazos entre actores) y por lo tanto -al contrario que la mayoría de los modelos estadísticos- no pueden ser construidos a partir de postulados de independencia de las observaciones. Así la tarea se vuelve mucho más compleja. El objetivo de estos modelos es explicar la probabilidad de la estructura observada de una red total, es decir, la organización de lazos entre los actores. Esta estructura observada es por lo tanto la variable dependiente y debe ser explicada a partir de un cierto número de efectos y de variables.

Los diferentes modelos desarrollados en la literatura de las redes sociales han mejorado considerablemente con el tiempo permitiendo incluir cada vez más efectos diferentes y a niveles diferentes: el nivel individual (las propiedades de los actores en la red), el nivel diádico (las propiedades de las relaciones) y el nivel triádico (estructuras típicas de relaciones entre tres actores) etc. Además, dado que la emergencia y evolución de una red es un proceso dinámico, es preferible utilizar un modelo que tenga en cuenta el paso del tiempo. En este punto la tarea se vuelve francamente compleja. Tal como lo discute van de Bunt (1999:27), la literatura sobre las redes sociales no ofrece muchos modelos formales que permitan expresar los aspectos dinámicos del desarrollo de una red de relaciones. La mayoría de los modelos son estáticos y sólo recientemente se dispone de modelos longitudinales.

A continuación se exponen brevemente algunos modelos estadísticos existentes para el análisis de las redes sociales. Esta exposición no pretende ser exhaustiva, tan solo se propone ofrecer una visión general de los desarrollos principales y de los modelos disponibles en la literatura de las redes totales ${ }^{2}$. En concreto se expondrán tres modelos para redes sociales basados en modelos loglineares que se han llamado: $p 1, p 2$ y $p^{*}$. A continuación explicaremos de modo más detallado el modelo dinámico SIENA. Éste último se diferencia de los precedentes porque se basa en procesos de cadenas de Markov, lo que permite un tratamiento longitudinal de los datos. Los que deseen más detalles y especificaciones matemáticas deberán dirigirse a la literatura de referencia de los autores de éstos modelos, la vocación de este artículo es ofrecer una exposición asequible y no demasiado técnica respecto a la formalización matemática.

\section{BREVE HISTOIRA DE LOS MODELOS ESTADÍSTICOS PARA LAS REDES SOCIALES}

Uno de los primeros modelos estadísticos para las redes sociales, desarrollado por Holland y Leinhardt (1981) y Wasserman (1987), se conoce bajo el nombre de $p 1$ o primer modelo de probabilidad ${ }^{3}$. Las técnicas de estimación lo-

2 Para mas detalles sobre los modelos ver Zeggelink 1993, Wasserman y Faust 1994, Leenders 1995, Snijders 1998, van de Bunt 1999, Carrington, Scott y Wasserman 2005.

3 Anteriormente Holland et Leinhardt (1976) ya habían propuesto el modelo estadístico UIMAN. La lista de tripletes mostrada más adelante en la Figura 1 proviene de su propuesta. 
glineares del modelo $p 1$ fueron desarrolladas por Wasserman et al. (Wasserman y Faust, 1994). Este modelo incluía en sus especificaciones el tratamiento de efectos individuales y diádicos: las características de los actores y las características de las relaciones entre ellos se utilizaban para explicar la existencia o no de relaciones en la red. Sin embargo no incluía efectos triádicos, no se examinaban las interdependencias de relaciones entre tres actores. Como efectos estructurales individuales permitía estudiar la popularidad de los actores (indigrees) o cómo el hecho de ser elegido por los otros actores incitaba a seguir acumulando relaciones (emitidas o recibidas) y de la actividad, o cómo el hecho de emitir muchas relaciones (outdegrees) incitaba a seguir acumulando relaciones (emitidas o recibidas). Tampoco permitía examinar el efecto de variables exógenas a la red, es decir, todas aquellas variables atributivas de los actores típicas en las explicaciones sociológicas, como la edad, el sexo, el estatus u otras caracteristicas individuales, variables que pueden ser cruciales en el desarrollo de la estructura de una red total. En cuanto a los efectos diádicos, este primer modelo sólo permitía tener en cuenta la reciprocidad de la relación (la probabilidad de que si una persona $i$ escoge a una persona $j$ esta persona $j$ escoja a su vez a la persona $i$ ) lo que se queda a un nivel meramente diádico del estudio de la estructura. El modelo no permitía estudiar efectos triádicos que implicasen más de dos actores en sus elecciones recíprocas. Este modelo puede ser considerado como un modelo de regresión logística bivariado (bivariate logistic régression model) para las díadas de una red. Todavía postulaba la independencia entre díadas, lo que impide un tratamiento triádico y por lo tanto plenamente estructural, sin embargo fue un punto de partida importante para la modelización estadística de las redes sociales.

Algunas de las limitaciones del modelo $p 1$ fueron superadas por el modelo p2 desarrollado por van Duijn (van Duijn et al. 2004, van Duijn 1995, Lazega y van Duijn 1997). El modelo p2 puede ser considerado como una versión con efectos aleatorios (random effects) o como una versión multinivel del modelo $p 1$. Los métodos de estimación para el modelo $p 2$ son complejos y todavía están siendo mejorados por van Duijn y Zijlstra. La aportación principal del modelo $p 2$ es que permite la inclusión en el modelo de variables individuales exógenas (toda variable atributiva de los actores) como variables independientes y también de más variables diádicas (como la similitud entre actores, los intercambios de recursos, las frecuencias de interacción, los contenidos de las relaciones o cualquier otra característica de éstas). Asimismo permite estudiar efectos de interacción entre las distintas variables explicativas y la reciprocidad de la relación. Por este motivo, el modelo $p 2$ es mucho más interesante para un análisis sociológico que el modelo $\mathrm{pl}^{4}$. Sin embargo de un punto de vista estructural, aunque aumente las posibilidades de análisis a nivel diádico, el modelo $p 2$ sigue $\sin$ incorporar efectos al nivel triádico, por lo tanto plenamente estructurales .

4 Para una ilustración del interés de este modelo en la sociología de las organizaciones ver Lazega 2001. 
En 1996 Wasserman y Pattison propusieron el modelo $p^{*}$ generalizando la distribución de grafos a partir de cadenas de Markov propuesta por Frank y Strauss (1986) y siguiendo la propuesta realizada por Frank (1991). Este modelo propone una formulación muy general capaz de representar cualquier distribución de probabilidades ${ }^{5}$ para un grafo orientado. Ésto permite una gran flexibilidad así como la incorporación de efectos triádicos.

Su ventaja es de algún modo también su inconveniente: esta formulación es tan general que exige encontrar las distintas formulaciones específicas para «rellenar» la fórmula y que se vuelva operativa. Desde su aparición en 1996 varios investigadores se han consagrado a la elaboración de este modelo (Wasserman, Pattison, Robins y otros). De hecho el procedimiento de estimación de los parámetros sigue siendo provisional, hasta hoy se utilizaba un procedimiento llamado pseudo probabilístico ( $p$ seudo-likelihood) que reduce el procedimiento de estimación a una regresión logística. Sin embargo las propiedades estadísticas de este procedimiento son por el momento desconocidas, lo que exige tomar los resultados con cierta reserva. Recientemente Snijders (2002) ha propuesto un procedimiento de estimación más fiable basado en las cadenas de Markov Monte Carlo.

El modelo $p^{*}$ ha permitido finalmente tener en cuenta, además de los efectos diádicos, todo tipo de análisis triádicos mediante el estudio de frecuencias de distintos tipos de tripletes en las tríadas. Si una tríada representa el conjunto de relaciones recíprocas (o no) entre tres actores (ver la Figura 1), un triplete representa la estructura de relaciones vista desde el punto de vista de uno de los actores que la componen $(\mathrm{ego})^{6}$. Un estudio de las frecuencias de tripletes representa sencillamente el número de veces que se encuentra un tipo de triplete particular en la red.

\subsection{El paso a los modelos dinámicos}

Hasta el momento, los modelos presentados son modelos estáticos, sin embargo, dado que las redes sociales son estructuras que se desarrollan y cambian con el tiempo, parecía necesario comprender el desarrollo de estas estructuras. Para ello era necesario desarrollar modelos con procedimientos que permitiesen tener en cuenta el paso del tiempo.

Un procedimiento alternativo al de los modelos loglineares propuesto por Wasserman (1980) y Wasserman y Iacobucci (1988) apto para estudiar el desarrollo de las redes sociales en el tiempo, es el uso de procesos de Markov. El uso de las cadenas de Markov presenta múltiples ventajas y un numero menor de in-

5 Para que una distribución de probabilidades pueda ser representada mediante un grafo es necesario que su soporte sea finito o discreto, caso que se da tratándose de redes de actores ligados por relaciones dicotómicas.

${ }^{6}$ Cada tríada puede contçener de 0 a 6 veces un triplete dado, cada tríada puede contener varios tripletes diferentes. 


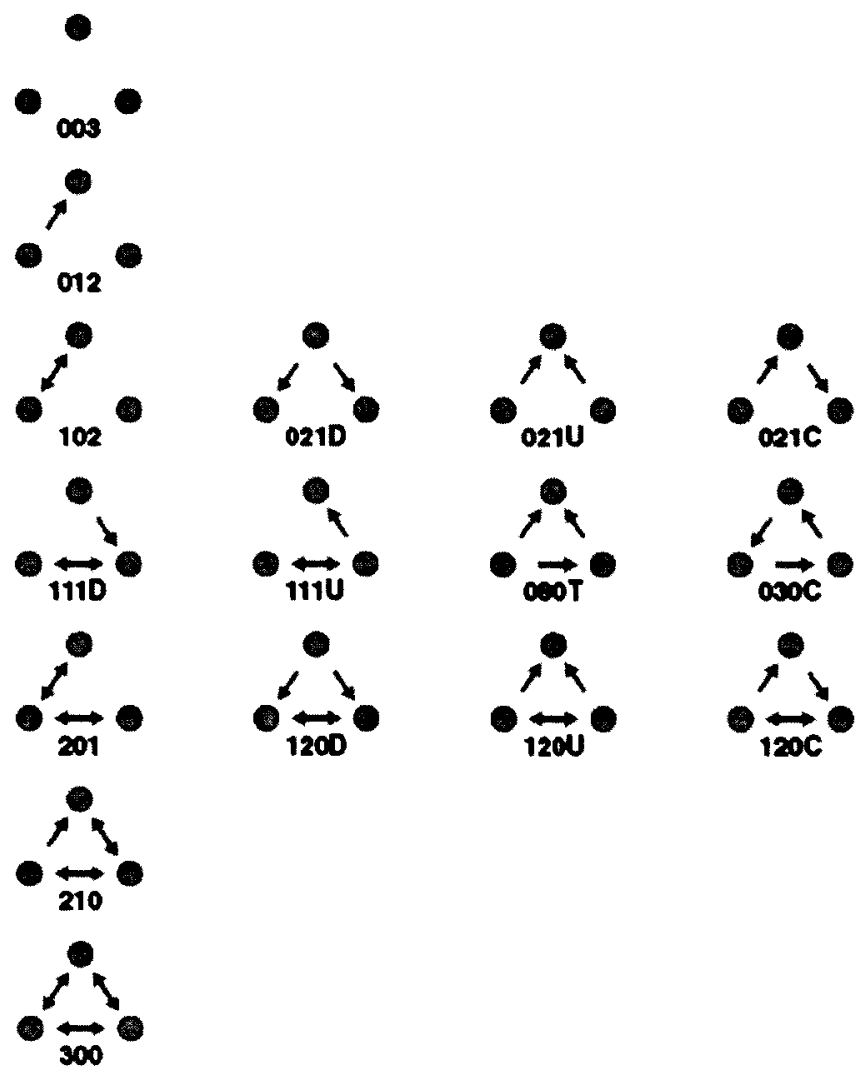

Figura 1. Clases isomórficas de las tríadas según Holland et Leinhard (1976).

convenientes que los modelos loglineares que van de Bunt (1999:31) resume de este modo:

1. El modelo loglinear permite manejar relaciones ordinalmente valoradas. El uso de las cadenas de Markov, tal como las aplicaciones lo utilizan hasta el momento, sólo permite considerar relaciones caracterizadas de forma dicotómica: o la relación existe o no existe. Dicho esto, el método utilizando cadenas de Markov puede ser ampliado en el futuro para varios valores. Este pequeño inconveniente provisional es compensado por las numerosas ventajas que se presentan a continuación.

2. El modelo loglinear produce demasiados parámetros. Si $g$ es el tamaño de la red estudiada, el modelo $p 1$ estima $2 g+1$ parámetros. Por ejemplo una red no muy grande, de 80 actores daría lugar a nada menos que $161 \mathrm{pa}-$ rámetros a examinar. 
3. El modelo loglinear sólo permite el uso de atributos nominales para caracterizar a los actores (p. ej. sexo), mientras que el modelo basado en cadenas de Markov permite el uso de atributos nominales y numéricos (p.e. edad). Además el análisis mediante cadenas de Markov permite la incorporación de un número mayor de atributos.

4. Los modelos fundados en cadenas de Markov se basan en procesos de tiempo continuo, lo que es más realista y al mismo tiempo permite interpretaciones mas naturales de los parámetros. En concreto permiten interpretaciones directas de los resultados de la evolución de una red sobre la que se dispone de varias observaciones con una periodicidad irregular (p. ej. una semana, un mes, seis meses y un año).

5. Los efectos estructurales, como la transitividad o la densidad son en general difíciles de representar, de hecho son imposibles de representar mediante modelos loglineares con la excepción de la reciprocidad, sin embargo se pueden representar con modelos fundados en cadenas de Markov. Esta es la cuestión clave que hace preferibles el uso de las cadenas de Markov para el modelado de redes sociales.

6. Los modelos mediante cadenas de Markov permiten fácilmente la simulación por ordenador.

Todo esto hace que, en conjunto, los modelos basados en cadenas de Markov sean más apropiados para el análisis longitudinal de redes.

\section{EL MODELO SIENA?}

El modelo SIENA ${ }^{8}$ (Simulation Investigation for Empirical Network Análisis $)^{9}$ desarrollado por Tom Snijders $(2001,2005)$ propone un modelo estadístico de análisis de datos longitudinales para redes totales. Para aplicarlo es necesario disponer de al menos dos observación del estado de una red total en dos momentos del tiempo ${ }^{10}$. Éstas observaciones dan lugar a dos matrices ${ }^{11}$ que repre-

7 Se describen aquí de forma principalmente «verbal» los principios de funcionamiento del modelo SIENA, Para obtener informaciones técnicas más detalladas véase Snijders (2005), Snijders (2001), Snijders y van Duijn (1997). La siguiente sección se puede considerar un resumen comentado de Snijders (2001).

${ }^{8}$ Los manuales prácticos, artículos y explicaciones completas a propósito de SIENA, así como el programa de análisis y algunos datos ilustrativos están disponibles de forma gratuita en la página web: http://statt.gamma.rug.nl/stocnet y http://statt.gamma.rug.nl/snijders/siena.html.

${ }_{9}$ Investigación mediante simulación para análisis de redes empíricas.

10 Aunque inicialmente era necesario que los actores miembros de la red permaneciesen estables entre las distintas observaciones, las últimas versiones de SIENA permiten cambios en la composición de la red siempre que esta no supere el $50 \%$ de los actores ver Huisman et Snijders (2003).

11 Dicha red puede ser representada como una matriz $n \times n$ llamada $x=\left(x_{i j}\right)$ en que $x_{i j}$ representa la relación dirigida del actor $i$ al actor $j(i, j=1, \ldots, n)$. Sólo se consideran relaciones dicotómicas, 
sentan al menos una situación inicial y una situación final, siendo posible observar e incluir el estudio de estados intermedios de la red ${ }^{12}$.

La variable dependiente analizada es el cambio de relaciones en la red representada mediante dos (o mas) grafos orientados cuyas relaciones son definidas de forma dicotómica (presencia o ausencia). SIENA estudia los factores que influyen el paso de la primera situación a la segunda (y la tercera y la cuarta...).

El modelo se apoya en la teoría de la acción orientada por un objetivo (purposive action) y postula que los actores escogen establecer, mantener o suprimir relaciones para maximizar su utilidad, lo que determina el devenir de la estructura de la red. El estado de una red en un momento dado condiciona los estados posteriores de esta; de este modo la red es considerada como una estructura que condiciona su propia evolución. Esta concepción coincide con la noción de estructura de Piaget (1968).

La evolución de la red es modelizada como el resultado de procesos estructurales, efectos exógenos y efectos aleatorios. El modelo permite por lo tanto estudiar el desarrollo de procesos estructurales a niveles diferentes, por ejemplo la evolución de la red mediante el proceso de establecimiento preferente de relaciones reciprocas (a nivel diádico) o el proceso de transitividad de las relaciones (a nivel triádico), el incremento de la densidad a nivel global, todos ellos procesos endógenos a la dinámica de una red.

También permite examinar los efectos de variables exógenas a la red como las características de los actores de la red (sexo, edad, tamaño del actor si es un actor colectivo); y ciertas covariables que dependen de pares de actores (la similitud respecto a una característica dada, la distancia geográfica entre estos... $)^{13}$.

Los modelos estadísticos utilizados son cadenas de Markov de tiempo continuo que pueden ser utilizados en modelos informáticos de simulación ${ }^{14}$. La evolución de la red es modelizada como la consecuencia de las nuevas elecciones de los actores de establecer, mantener o suprimir una relación existente basándose en funciones con componentes fijos y aleatorios que los actores tratan de maximizar. Los parámetros del modelo deben ser estimados a partir de datos empíricos. Para estimar y someter a prueba estos modelos, SIENA utiliza procedi-

la relación entre $i$ y $j$ está presente $x_{i j}=1$ o ausente $x_{i j}=0$. No se consideran las auto-relaciones así pues los valores de la diagonal carecen de sentido. Esta $x$ es la matriz de adyacencia del grafo dirigido mediante el que se puede representar la red (Snijders 2001, pp. 361-362).

${ }^{12}$ Se consideran datos longitudinales de redes totales siguiendo una serie temporal $x(t), t \in t \mid t_{1}$, $\left.\ldots, t_{M}\right\}$ para, en principio, un número constante de actores $\{1, \ldots, n\}$. Los momentos de observación están ordenados: $t_{1}<t_{2},<\ldots<t_{M}$. El número $M$ de observaciones es por lo menos 2 .

13 También se pueden incluir como variables «exógenas « los otros tipos de relaciones existentes entre estos actores. Por ejemplo si se modeliza la evolución de una red de intercambio de consejos entre miembros de una empresa, se puede introducir como variable explicativa la existencia de relaciones de amistad entre ellos.

14 Ver Snijders (2001) páginas 364-365 para la formulación matemática respecto al uso de cadenas de tiempo continuo de Markov en el modelo SIENA. 
mientos estadísticos basados en el método de los momentos ${ }^{15}$. Los procedimientos estadísticos son puestos en funcionamiento utilizando un algoritmo de aproximación aleatoria ${ }^{16}$ fundado en simulaciones por ordenador del proceso de evolución de la red.

Uno de los intereses de este programa es que permite controlar recíprocamente los efectos de las variables que se han incluido en el análisis, lo que es particularmente importante en el caso de los procesos estructurales: la transitividad es controlada por la reciprocidad y ambas por la densidad de la red.

SIENA trabaja, por el momento, sólo con relaciones definidas de manera dicotómica, es decir cada matriz de relaciones observadas debe expresar la presencia o la ausencia de una relación definida según los criterios del investigador. Sin embargo es posible incluir, como variables diádicas exógenas, distintas medidas de intensidad de las relaciones e incluirlos en el modelo. Por ejemplo se puede estudiar la probabilidad de una relación de perdurar en función de la frecuencia de interacción (o la intensidad subjetiva) medida mediante una escala en un periodo anterior de la relación. No obstante es necesario que las variables en cuestión sean exógenas respecto al tipo de relación específicamente estudiada.

Las relaciones son relaciones dirigidas, lo que indica que en la matriz, la línea de un actor representa las relaciones que este dice escoger o emitir hacia otros actores de la red, y la columna de este mismo actor representa las elecciones que recibe por parte de otros actores de la red. Esto produce matrices potencialmente asimétricas (los actores no son necesariamente escogidos por aquellos que ellos escogen). Las relaciones de un actor consigo mismo no son tenidas en cuenta.

\subsection{Postulados del modelo}

El conjunto de las socio-matrices (todas las matrices $n \times n$ de elementos 0-1) se llama $X$ y posee $2^{n(n-1)}$ elementos -o posibles relaciones entre actores- lo que es un número enorme para utilizarlo en cálculos matemáticos. Para evitar cálculos imposibles, el modelo asume un cierto número de postulados más o menos realistas, necesarios para la modelización matemática ${ }^{17}$ :

1. Los actores de la red pueden evaluar su posición en la red y tratar de obtener una configuración de relaciones que consideren positiva.

2. Dada una configuración particular de la red, el modelo postula que todos los actores de forma independiente, es decir sin coordinación. Sin embargo la evolución dinámica asegura una dependencia de los cambios consecutivos efectuados por los actores.

15 Para más detalles de la formalización matemática ver Snijders (2001) p. 372 y siguientes bajo el epígrafe Moment estimators.

${ }_{16}$ Para más detalles de la formalización matemática ver Snijders (2001) p. 377 y siguientes bajo el epígrafe Stochastic approximation.

17 Para más detalles de la formalización matemática ver Snijders (2001) pp. 365-366. 
3. El modelo postula que los actores tienen un conocimiento total del estado de las relaciones en la red.

4. Cada actor escoge sus relaciones.

5. Se supone que los cambios tienen lugar uno detrás de otro y que todos los actores tienen la misma probabilidad de realizar un cambio.

6. Entre los momentos de observación de la red suceden cambios no observados.

7. Los estados futuros de la red son una función del presente, se considera que el pasado pertinente está contenido en el presente, lo que significa que el modelo trabaja como si los actores no tuviesen memoria del pasado ni capacidad de aprendizaje.

8. Los actores son considerados «miopes» es decir que su elección es un intento de maximización inmediata de su utilidad. No se considera que tengan estrategias a largo plazo.

Todo ello representa la idea de que los actores persiguen sus propios objetivos bajo las limitaciones impuestas por su entorno, al mismo tiempo que constituyen el entorno cambiante de los demás. La función objetiva expresa los objetivos que los actores quieren obtener a corto plazo.

Esta evaluación se define como la función de la posición del actor en la red y depende de parámetros estimados a partir de datos empíricos. El modelo incluye un elemento aleatorio para dar cuenta de la desviación entre las precisiones teóricas y las observaciones reales. Este elemento aleatorio da cuenta de a) las variables que tienen un rol pero que son desconocidas por el investigador y por lo tanto no están presentes en el modelo y/o b) los efectos de la ignorancia de los actores a propósito de la situación real de la red o de una mala evaluación sobre la mejor acción a llevar a cabo.

Los modelos pueden ser implementados como modelos de simulación aleatoria. Se trata de un procedimiento frecuencial que utiliza el método de momentos. El algoritmo de aproximación aleatoria es una derivación del algoritmo de Robbins-Monro (1951).

Se postula que la magnitud de los efectos que influyen en el cambio de la red se mantienen constantes a lo largo del tiempo entre las observaciones de la red. Se considera que, durante periodos breves en contextos precisos, los efectos no aumentan ni disminuyen en importancia. Si se tienen razones para pensar que diferentes efectos tienen una importancia diferente en distintos momentos, es preciso realizar varias observaciones (tal como hacen van de Bunt 1999, Zeggelink et al. 1997, Zeggelink et al. 1999, van Duijn et al. 2003). Si el tiempo entre dos medidas es demasiado grande, puede ser que la situación inicial ya no sea pertinente para explicar la situación final. En cuyo caso SIENA analizaría los datos con menor habilidad. 


\subsection{Discusión de los postulados del modelo}

El realismo de los postulados con los que SIENA está construido son discutibles de un punto de vista teórico, aunque se admita que de un punto de vista técnico es difícil proceder de otro modo. En general este tipo de ideas se adaptan mejor a relaciones de tipo voluntario o afinitario. Se podría argüir que:

1. La idea de una evaluación por parte del actor y el intento de optimización de su posición en una red implica una visión consecuencialista e instrumentalista de las acciones del actor. Tal como diría Boudon (1984), esto implica que el actor oriente su acción teniendo en cuenta las consecuencias de lo que hace, que entre el conjunto de consecuencias que percibe, no presta atención mas que a aquellas que le interesan. Una aproximación dentro de la teoría de la elección racional clásica afirmaría que el actor es capaz de determinar los costes y beneficios de sus acciones. Sin embargo no hay acuerdo en la literatura sociológica y antropológica a propósito de las relaciones personales (amistad, parentesco) en este punto. Algunos autores (Bloch y Buisson 1991, Bidart 1991, Godbut y Charbonneau 1993) afirman que cuando los actores centran su atención en equilibrar los costes y beneficios de las relaciones estamos frente a situaciones de crisis : el estado normal de las relaciones personales sería el de la mutualidad altruista y no contabilizada. Otros, como van de Bunt (1999) dirían más bien lo contrario. La aproximación del modelo de SIENA no va tan lejos, dado que considera que los actores son miopes y no realmente capaces de determinar dichas relaciones de costes y beneficios a la manera de la teoría de la elección racional, se trata de un modelo de acción con objetivos a corto plazo.

$\mathrm{Si}$ admitimos que los actores son estratégicos y evalúan sus posiciones para tratar de mejorarlas por medio de cálculos racionales de costes y beneficios - incluso a corto plazo - entonces este postulado se adapta mejor a tipos de relaciones más bien voluntarias sobre las que no pesan normas sociales muy restrictivas (como las relaciones de amistad) y en que los márgenes de maniobra de los actores son relativamente amplios. Dicho esto, también es posible incluir variables para tener en cuenta los efectos de las normas en el modelo y estimarlas entre otros efectos.

Los autores del modelo no afirman que la evaluación en vista de la optimización de la red que los actores realizan sea necesariamente consciente o intencional. Lo único que afirman es que la red puede ser modelizada como si cada actor tratase de obtener una configuración óptima de sus relaciones. Esta forma de comprender la evolución de las redes sociales está de acuerdo con el principio teórico del individualismo metodológico (Degenne y Forsé 1994) que Snijders llama aquí modelo aleatorio orientado al actor (stochastic actor-oriented model). A partir de los resultados de la modelización, se pueden encontrar las limitaciones, los efectos de normas, o las preferencias fuertes que se dan en la red. 
2. La independencia de la acción de los actores, la falta de coordinación, se adapta sin duda mejor a las relaciones voluntarias y de carácter privado. Aún así, en la literatura antropológica sobre la amistad se encuentran fenómenos de exclusión colectivos de grupos de amigos, por ejemplo en los modelos de amistad de las «cuadrillas» (Cucó i Giner 1998), en que la aceptación de nuevos miembros por el grupo de amigos o su exclusión son el fruto de decisiones fuertes y colectivas. Para el tratamiento matemático se hace como si cada uno de estas elecciones tuviese lugar de forma independiente y en momentos diferentes, que pueden ser muy próximos en el tiempo. Dicho tratamiento puede ser considerado aceptable para tales casos porque de algún modo hay una serie de decisiones individuales en este proceso de grupo sobre la aceptación o la exclusión de alguien ( $y$ de hecho es posible encontrar disidente en el seno de estos procesos de grupo).

3. El postulado sobre el conocimiento total de la estructura de la red por los actores no es en absoluto realista, particularmente para grandes redes. Es muy difícil conocer el estado preciso de las relaciones entre actores de una red, como mucho, es posible representarse su estado, lo que bien puede no coincidir con la realidad. Para las relaciones de carácter privado, por ejemplo las relaciones de amistad, que pueden desligarse del contexto inicial de formación (Allan 1989), no siempre es posible conocer la existencia de un lazo particular entre dos personas más allá de su relación cordial, incluso cuando su interacción es parcialmente observable. Algunos tipos de relaciones son más o menos visibles para otros miembros de la red ${ }^{18}$. Además, tal como lo indica Ferrand (1997, p. 44) los actores encuentran dificultades cognitivas y semánticas para representarse las relaciones indirectas, incluso en el caso de relaciones de parentesco cuyo vocabulario es uno de los más ricos. Tal vez el conocimiento del estado de la red a una distancia 2 (el actor conoce las relaciones de las personas con quienes tiene un lazo directo) sería más realista.

Los postulados 4,5 y 6 son bastante razonables para relaciones de carácter voluntario.

4. En el caso de las relaciones de amistad, por ejemplo, se puede considerar que, dado un contexto, éstos pueden escoger a sus amigos entre las relaciones posibles y disponibles.

5. Incluso si los cambios no tienen lugar uno tras otro, de forma necesariamente diacrónica, sino también de forma sincrónica, como podrían afirmar las teorías sobre el ajuste recíproco, este postulado no es molesto. Es posible proceder como si un intervalo existiese entre el momento en que un actor entra en conflicto con otro y el momento en que el otro hace lo

${ }^{18}$ De hecho, si este postulado fuese realista la vida de los analistas de redes sociales sería mucho más fácil. Véase Ferrand y Snijders (1997) para una discusión sobre este tema a propósito de las relaciones sexuales. 
propio, incluso si este desfase es infinitesimal. Se puede hacer como si estos intervalos fuesen regulares para el modelo matemático, aunque no lo sean en la vida real. Recordemos que estamos frente a un instrumento para obtener indicadores que nos ayudan a interpretar la realidad y no una interpretación sobre cómo suceden realmente.

6. El hecho de que los cambios sucedan entre los momentos de observación de la red es perfectamente realista.

7. El postulado de que toda información pertinente del pasado está contenida en el presente puede ser «corregida» por medio de variables adicionales. Por ejemplo, si tenemos razones para pensar que la inestabilidad de una relación en el pasado (su alternancia entre presencia y ausencia) puede explicar los estados futuros de esta (p.e. que las relaciones inestables tienen más probabilidades de ser eliminadas que las estables), es posible crear variables que describan dicha inestabilidad e incluirlas en el modelo.

8. El postulado de la intención no estratégica a largo plazo, sino de satisfacción inmediata se adapta bien a ciertos tipos de relaciones, pero no a todas. Es pertinente, una vez más, para las relaciones de amistad, en que las estrategias estructurales a largo plazo - p. ej. quiero ser amigo de $X$ porque $\mathrm{X}$ es amigo de $\mathrm{Y}$ - aunque posibles, estarían mal vistas, dado que son opuestas al modelo ideal de la amistad. Para las relaciones de amistad, se puede decir que el modelo representa actores "de buena fé", sin embargo, para otro tipo de relaciones, los actores podrían tener estrategias relacionales de distancia 2 o mayores.

A pesar de todas estas consideraciones y matizaciones, se puede considerar que el uso de este modelo aporta conocimientos válidos sobre el proceso de emergencia de los lazos en una red. Es posible «minimizar» los problemas que podrían inducir los postulados que acabamos de discutir gracias a una selección guiada teóricamente de las variables incluidas en el modelo.

\section{LA ESPECIFICACIÓN DE SIENA}

El modelo utilizado por SIENA contiene 3 elementos:

a) La función objetiva (objective function)

b) La función de velocidad (rate function)

c) La función de dotación (endowment function)

En esta sección, se aborda la especificación simple del modelo, determinada solo por la función objetiva, con una función de velocidad constante, y una función de dotación igual a 0 . En principio el modelo de base incluye solamente la función objetiva. Las dos otras funciones serán discutidas más adelante. 


\subsection{Componentes del modelo de base: la función objetiva}

La función objetiva ${ }^{19}$ para un actor $i$ indica el grado de satisfacción del actor $i$ inherente a la configuración $x$ de la red. En un momento $t$ el actor $i$ tiene la oportunidad de cambiar una relación (comenzar, mantener o disolver una relación). Se postula que el actor $i$ escoge la acción respecto al actor $j$ que maximiza el valor de la función objetiva. La función incluye un elemento aleatorio que indica las preferencias del actor que no son representadas por los componentes que se están estudiando.

El modelo supone que aunque existan diferencias entre los actores respecto a sus preferencias, estas diferencias son capturadas (expresadas) por las variables exógenas. Por ejemplo, si ciertos actores tienen una mayor preferencia por la reciprocidad que otros, debería existir una variable $W$ observada de forma que la interacción entre $W$ y el efecto de la reciprocidad puede representar esas preferencias diferenciales.

\subsection{Efectos de la función objetiva}

En esta sección se describen algunos de los principales efectos que se pueden estudiar con SIENA ${ }^{20}$. La función objetiva debe contener los efectos componentes sustantivos del modelo, incluyendo, por ejemplo, los atributos del actor y las propiedades estructurales del grafo orientado que se quiere estudiar. La función se define con la idea de que cada actor controla solo las elecciones que decide establecer, mantener, interrumpir, pero no las elecciones de los demás. Los efectos principales incluidos en la función objetiva son:

1. Densidad: definida por las relaciones emitidas por el actor $i^{21}$.

2. Reciprocidad: definida por el número de relaciones recíprocas (si $i$ emite una relación hacia $j$ y $j$ emite una relación hacia $i$ ). La reciprocidad expresa la preferencia por relaciones recíprocas: es más «interesante» escoger como amigo a alguien que ya os considera como amigo que alguien que no lo hace 22 .

3. La popularidad: definida como la suma de relaciones recibidas por los actores $j$ con los que $i$ está en relación (grado interior del asociado). El efecto de popularidad refleja la preferencia de estar ligado a actores populares. Puede reflejar efectos de aspiración de status ${ }^{23}$.

${ }^{19}$ Para más detalles de la formalización matemática ver Snijders (2001) pp. 366-368.

${ }^{20}$ Las distintas versiones de SIENA van ampliando la lista de efectos que se pueden estudiar añadiendo versatilidad y sofisticación al modelo.

21 Para más detalles de la formalización matemática ver Snijders (2001) p. 369, punto 1.

22 Para más detalles de la formalización matemática ver Snijders (2001) p. 369, punto 2.

${ }^{23}$ Para más detalles de la formalización matemática ver Snijders (2001) p. 370, punto 3. 
4. La actividad: definida por la suma de las relaciones emitidas por los actores $j$ con los que $i$ está relacionada (grado exterior del asociado). El efecto de la actividad refleja la preferencia de estar ligado con actores que emiten muchas relaciones ${ }^{24}$.

5. Efectos de cierre de una red que se pueden definir de diferente modo: Transitividad: definida por el nombre de tripletes transitivos entre las relaciones de $i$ ( $i$ está en relación con $j$ y $h$, y estos están en relación entre ellos) ${ }^{25}$. Relaciones indirectas: definida por el nombre de actores con los que $i$ está en relación indirecta, con una distancia sociométrica de 2 , es decir con un intermediario ${ }^{26}$. Equilibrio (balance): definida por la similitud entre las relaciones emitidas por el actor $i$ comparadas con las relaciones emitidas por el actor $j$ con el que $i$ está en relación ${ }^{27}$. La transitividad de los tripletes expresa que un actor $i$ estará más atraído por un actor $j$ si existen más conexiones indirectas $i \rightarrow h \rightarrow j$; un efecto negativo de las conexiones indirectas expresa que $i$ estará más atraído por $j$ si hay al menos un lazo indirecto entre los dos. El efecto de equilibrio expresa que $i$ prefiere estar ligado con los $j$ que realizan elecciones parecidas a las de él. La lista puede aumentar, pero por el momento estos son los efectos incluidos.

Es aconsejable incluir siempre la densidad en el modelo puesto que es un efecto de control para los de más efectos estructurales.

Para las variables exógenas dependientes de los actores, SIENA propone varios efectos fundamentales. Resultan de particular interés:

6. La homofilia ligada a una variable, definida por la suma de las diferencias absolutas entre el valor de la variable para $i$ y todos los otros con los que $i$ está en relación. Cuando la similitud es positiva ello indica la preferencia por personas de mismas características (sexo, nacionalidad, clase social.... ${ }^{28}$.

7. Las preferencias ligadas a una variable diádica definida por la probabilidad de un lazo entre $i$ y $j$ aumentan si la variable diádica es más elevada para esos actores ${ }^{29}$.

8. Interacciones entre la reciprocidad y las variables diádicas.

El tipo de efectos y variables a incluir en el modelo dependen evidentemente, del objeto de estudio y de las orientaciones teóricas adoptadas.

${ }^{24}$ Para más detalles de la formalización matemática ver Snijders (2001) p. 370, punto 4.

${ }^{25}$ Para más detalles de la formalización matemática ver Snijders (2001) p. 370, punto 5.

${ }^{26}$ Para más detalles de la formalización matemática ver Snijders (2001) p. 370, punto 6.

27 Para más detalles de la formalización matemática ver Snijders (2001) p. 370, punto 7.

28 Para más detalles de la formalización matemática ver Snijders (2001) p. 371, punto 10.

29 Para más detalles de la formalización matemática ver Snijders (2001) p. 372, punto 11.

${ }^{30}$ Para más detalles de la formalización matemática ver Snijders (2001) p. 382, y siguientes. 


\subsection{El modelo extendido: la función de velocidad y la función de dotación}

Además de la función objetiva que puede contener los efectos de los que acabamos de hablar, SIENA comprende otras dos funciones más: la función de velocidad (rate function) y la función de dotación (endowment function). Estas dos funciones se añaden para expresar efectos que no pueden ser contenidos en la función objetiva. La función de velocidad ${ }^{30}$ tiene como objetivo dar cuenta del hecho de que la velocidad de cambios de la estructura de la red puede variar, y que esos cambios de velocidad pueden estar ligados a ciertas características de los actores, de las relaciones o de la estructura de la red. Algunos de los efectos de esta función:

1. Efecto de base: éste forma parte del modelo de base y simplemente da cuenta de la velocidad a la que cambian las relaciones ${ }^{31}$.

2. Efecto de la reciprocidad sobre la velocidad. Permite poner a prueba si los actores con relaciones recíprocas cambian más (o menos) velozmente que los actores con menos relaciones recíprocas. Para las relaciones de amistad, por ejemplo, se podría esperar que los actores con relaciones recíprocas las cambien a menor velocidad ${ }^{32}$.

3. Efectos de atributos de los actores sobre la velocidad. Gracias a este efecto, se puede examinar cómo las diferentes características de los actores pueden jugar sobre la velocidad de cambio de las relaciones. Por ejemplo se podría examinar si los hombres cambian sus relaciones más deprisa que las mujeres ${ }^{33}$.

La función de dotación ${ }^{34}$ pretende dar cuenta de que un mismo efecto puede ser más o menos importante cuando se trata de la creación de una relación que de cuando se trata de su ruptura. El proceso de ruptura no es exactamente inverso al de creación de una relación. Esto se debe a las inversiones de tiempo y otros recursos no recuperables que se emplean en las relaciones o a los costes y sanciones diádicas o triádicas que pueden implicar las rupturas. Gracias a esta función se pueden estudiar los factores que aumentan los costes de la ruptura de una relación. Algunos de los efectos incluidos:

1. Ruptura de relaciones recíprocas. Típicamente se puede considerar que, en el caso de la amistad por ejemplo, será más costoso romper una relación recíproca que una relación asimétrica ${ }^{35}$.

${ }^{31}$ Para más detalles de la formalización matemática ver Snijders (2001) p. 383, punto 1.

${ }^{32}$ Para más detalles de la formalización matemática ver Snijders (2001) p. 383, punto 3.

${ }^{33}$ Para más detalles de la formalización matemática ver Snijders (2001) p. 383, punto 2.

${ }^{34}$ Para más detalles de la formalización matemática ver Snijders (2001) p. 384 bajo el epígrafe Gratification function o función de gratificación. Con posterioridad Snijders (2005) llama a esta misma función endowmen function o función de dotación.

35. Para más detalles de la formalización matemática ver Snijders (2001) p. 385, punto 1. 
2. El ruptura de relaciones con acceso indirecto. Permite examinar si, en algunos modelos relacionales, es más costoso romper una relación ya imbricada que una relación aislada ${ }^{36}$.

3. Ruptura de las relaciones según una variable diádica. Muestra cómo las características de la relación (p. ej. flujo, frecuencias, intensidad...) hacen que su ruptura sea más o menos difícil.

4. Ruptura de las relaciones según una disimiltud. Examina si individuos diferentes respecto a un criterio (p.e. sexo, nacionalidad) terminan su relación con mayor o menor facilidad ${ }^{37}$.

Cualesquiera que sean las componentes que se utilizan en el modelo, éste debe ser construido con parsimonia, incluyendo solamente 2 o 3 efectos adicionales cada vez que se lanza el procedimiento. En cada tentativa se eliminan los efectos no significativos y se pueden añadir de nuevo 2 o 3 variables suplementarias. Los efectos estudiados se controlan mutuamente. Los resultados presentan un parámetro y su desviación típica. Hay que leerlos como distribuciones T-test, es decir que se considera que un parámetro es significativo cuando su valor es al menos el doble de su desviación típica ${ }^{38}$. Cuanto mayor la razón entre el parámetro y su desviación típica, mayor la certeza de su significatividad, sin embargo es difícil pronunciarse sobre la magnitud de los efectos o compararlos entre ellos, dado que la interpretación del valor del parámetro depende de la distribución precisa de los valores en cada variable.

\section{UN EJEMPLO DE APLICACIÓN. LA EVOLUCIÓN DE UNA RED DE AMISTAD INTERNACIONAL}

Seguidamente se ilustran las potencialidades de SIENA mediante un ejemplo de aplicación: la evolución de una red de amistad de estudiantes Erasmus. Este caso ya ha sido expuesto con anterioridad (ver de Federico 2003a, 2003b) en el presente artículo la presentación se reduce a lo indispensable para ilustrar la utilización de SIENA. Los estudiantes Erasmus, más de 1,3 millones desde la creación del programa por la Unión Europea, realizan una estancia de entre 3 y 12 meses en una universidad de otro país europeo.

Los datos presentados aquí provienen de una investigación que evalúa el impacto de las relaciones de amistad creadas durante el periodo de intercambio Erasmus sobre las actitudes hacia Europa y los Europeos, y sobre la identificación con ésta. La investigación contaba con dos partes, la primera se dedicaba a examinar las relaciones de amistad y su dinámica, la segunda a estudiar de forma

${ }^{36}$ Para más detalles de la formalización matemática ver Snijders (2001) p. 385, punto 2.

${ }^{37}$ Para más detalles de la formalización matemática ver Snijders (2001) p. 385, punto 3.

${ }^{38}$ Más precisamente si $1,65<t<1,96 ; p<0,10$; si $1,96<t<2,53$; $p<0,05$; si $2,53<t<3,29$; $p<0,01$ y si $t>3,29 ; p<0,001$. 
sistemática los efectos de tales relaciones de amistad sobre las representaciones, actitudes y sentimientos de pertenencia respecto a Europa y la UE.

Los análisis aquí presentados forman parte de la primera parte.

Antes de mostrar la aplicación de SIENA para explicar la evolución de esta red, es conveniente caracterizar brevemente las relaciones de amistad a partir de la literatura y describir brevemente la red estudiada.

\subsection{Las relaciones de amistad ${ }^{39}$}

Paine (1969), Allan $(1979,1989)$ definen la amistad como una relación personal, voluntaria y principalmente afectiva. La vida de las personas es mucho más agradable teniendo amigos que sin tenerlos. Los amigos nos aceptan «tal y como somos» (Allan 1989, Bidart 1991, 1993) y nos hacen la vida más fácil y cómoda. Comparten nuestros intereses e ideas (Lazarsfeld y Merton 1954, Bidart 1991), nos ayudan con las cuestiones de la vida cotidiana (Wellman et al. 1988, Wellman y Wortley 1990) al igual que en los grandes momentos de crisis (Ferrand 1993, Bidart 1993). Las amistades son formadas en contextos sociales y son sometidas a normas y modelos sociales. Para empezar y como mínimo, es necesario estar en el mismo lugar en el mismo momento y con una actividad que permita una interacción mínima, para poder conocer a alguien, descubrimos afines y devenir amigos. Por consiguiente, para la formación de relaciones de amistad existe una estructura de oportunidades subyacente a aspectos meramente geográficos (dónde pasamos nuestro tiempo), pero también a la interdependencia funcional en foci de actividad (lo que hacemos y las interacciones que tal actividad permite) (Feld 1997, Flap y Volker 2002). A partir del momento en que la interacción es posible, en general parece ser que las personas prefieren como amigos a sujetos similares social y personalmente (Heider en Perlman y Fehr 1986). Por otra parte, las relaciones se establecen a menudo a partir de otras relaciones (Hallinan 1979, Ferrand et al. 1999). Nuestras redes personales nos permiten tener acceso a nuevos contactos: los amigos de mis amigos se convierten en mis amigos (Granovetter 1973, Degenne y Forsé 1994). Al mismo tiempo éstas también las limitan: los enemigos de mis amigos no pueden ser mis amigos (Lorrain y White 1971, Pizarro 2004).

Hasta aquí hemos mencionado factores clásicos en la teoría de la amistad (van de Bunt 1999): partiendo de una preferencia por tener amigos, hemos mencionado la importancia de la estructura de oportunidades, la preferencia por la similitud, y el acceso condicionado a nuevas relaciones a partir de las precedentes.

En este punto, y para el caso estudiado, es pertinente recordar que, aunque en general en las sociedades occidentales la amistad sea una relación personal,

${ }^{39}$ Una excelente síntesis en castellano de la investigación sociológica sobre la amistad puede ser encontrada en Requena (1994). 
privada, voluntaria y no ritualizada (Paine 1969), su definición, contenido y expectativas pueden variar de una sociedad a otra. Esto se refleja por ejemplo el vocabulario diferente que se emplea en distintos países para referirse a ésta, en francés existe una distinción entre ami y copain que representa una relación amistosa pero más ligera que la de amistad. En inglés británico ésta distinción existe entre friend y mate (Allan 1979, 1989), mientras que los estadounidenses utilizan solamente friend para distintos grados de profundidad en la relación amistosa (Fischer 1982). En español se utiliza también una sola palabra para diferentes matices de la relación y en griego moderno el término para designar a los amigos es incluso más amplio: la palabra $\varphi \imath \lambda o \zeta$ incluye también al novio o novia. El contenido específico de las relaciones se comprende según el contexto social y semántico. Es esperable por lo tanto encontrar diferencias respecto a la forma de comprender la amistad según los países.

\subsection{La red de estudiantes Erasmus}

La red estudiada incluye 80 estudiantes provenientes de 9 países Europeos ${ }^{40}$ acogidos a partir del mes de octubre en la Universidad de Lille 1 en 1995 en el marco del programa Erasmus. Se realizaron varias observaciones del estado de esta red. La primera corresponde al momento de su llegada a Francia en el mes de octubre. La segunda tuvo lugar en febrero de 1996, cuatro meses más tarde y antes del regreso de los primeros estudiantes. La tercera, un año después del final del intercambio Erasmus, ésta última obtuvo una tasa de respuesta insuficiente para incluirla en el análisis. El generador de nombres utilizado proponía una definición amplia de la amistad: «¿Podrías mencionar el nombre de todos tus amigos durante tu estancia Erasmus?" ${ }^{41}$ Esta pregunta pretendía capturar todo tipo de amistades de intensidades variadas. Las relaciones de amistad y los amigos eran caracterizados a continuación de forma detallada.

En el momento de la primera descripción de la red, las relaciones de amistad eran poco numerosas dado que los estudiantes acababan de llegar a Francia. Las pocas relaciones existentes correspondían a relaciones anteriores al intercambio, es decir, a los casos en que los estudiantes se desplazaban acompañados por otros amigos o por su pareja.

No había en la universidad de Lille arreglos institucionales que favoreciesen particularmente la interacción exclusiva entre estudiantes Erasmus, y de hecho se utilizó un protocolo de análisis de redes personales, sin embargo $80 \%$ de los amigos de los estudiantes Erasmus eran otros estudiantes Erasmus. Sólo 17\% de los amigos eran estudiantes franceses y el $3 \%$ restante tenía otros orígenes no europeos.

40 Alemania, Austria, Bélgica, España, Gran-Bretaña, Grecia, Italia, Portugal y Suecia.

${ }^{41}$ La pregunta original en francés era: «Pouvez vous mentionner le nom de vos amis et copains lors de votre séjour Erasmus». Nótese la distinción entre ami y copain, inexistente en castellano.

EMPIRIA. Revista de Metodología de Ciencias Sociales. N. ${ }^{\circ}$ 10, julio-diciembre, 2005, pp. 151-181. 
La auto-selección en el seno de la propia población resulta abrumadora si se considera que dichos estudiantes no constituían más que el $1,7 \%$ de la población total de la Universidad de Lille y que se encontraban dispersos en disciplinas, diplomas y lugares de residencia distintos y en que eran minoritarios. Dada la constitución de un círculo social de estudiantes Erasmus, resultaba pertinente de un punto de vista sustantivo reconstruir la red total de los estudiantes Erasmus. Se reconstituyó entonces el estado de la red de amigos de los estudiantes a dos momentos diferentes que llamaremos $t 0$ (momento de llegada a Lille) y $t 1$ (cuatro meses más tarde). La red cambió mucho entre estos dos momentos como se puede observar a partir de los grafos realizados con Pajek (ver las Figuras 2 y 3 ).

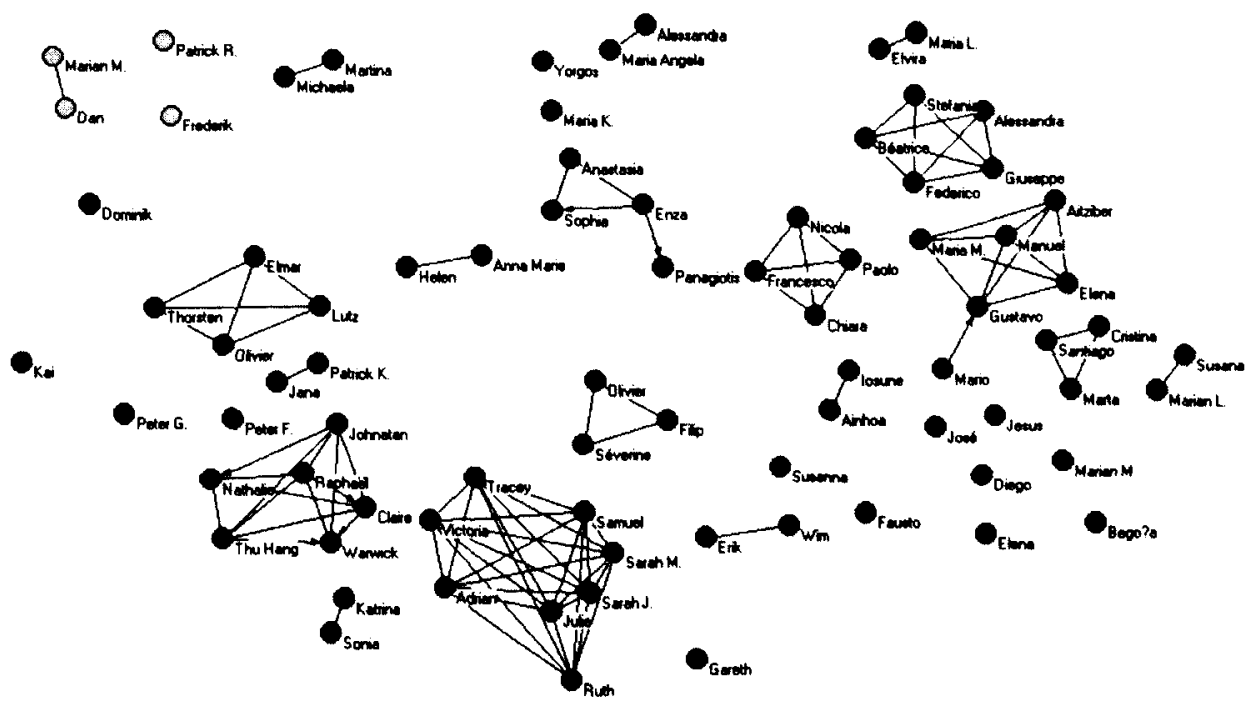

Figura 2. Red de amigos Erasmus en t0.

Leyenda para las figuras 2 y 3 :

$\begin{array}{llllll}\text { Rojo: } & \text { Españoles } & \text { Azul oscuro: } & \text { Griegos } & \text { Verde: } & \text { Alemanes } \\ \text { Negro: } & \text { Británicos } & \text { Azul claro: } & \text { Suecos } & \text { Violeta: } & \text { Belgas } \\ \text { Naranja: } & \text { Italianos } & \text { Verde claro: } & \text { Austríacos } & \text { Amarillo: } & \text { Portugueses } \\ \text { Flechas negras: } & \text { Relaciones dirigidas. } & & & \end{array}$

Líneas azules: Relaciones recíprocas.

Si se examinan las características de la red en estos dos momentos de forma sistemática se puede constatar que en $t 0$ la red estaba prácticamente vacía. El número medio de amigos en la red no llegaba a uno. El número de elecciones de amistad emitidas variaba entre 0 y 7 . La densidad y la transitividad eran muy bajas. Sin embargo la reciprocidad resultaba muy elevada (ver la Tabla 1). 


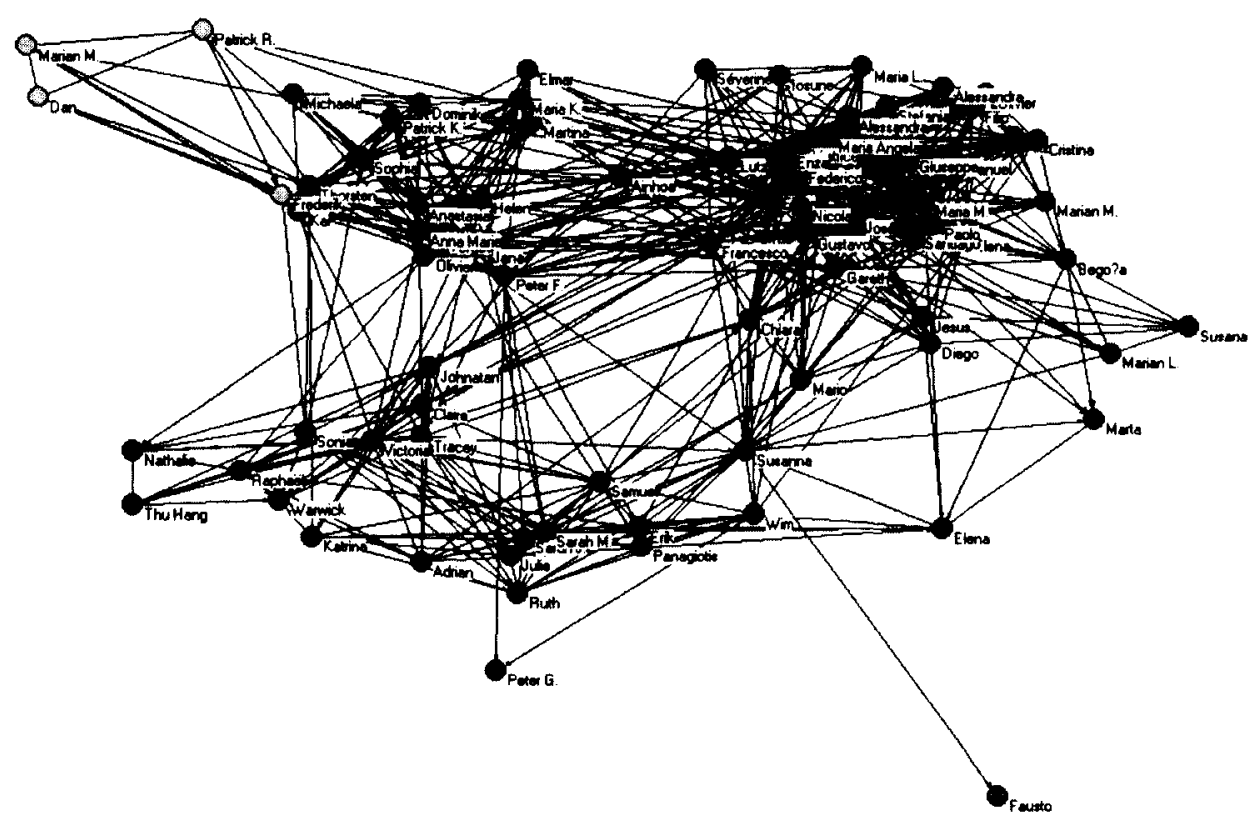

Figura 3. Red de amigos Erasmus en 1 .

Tabla 1

Características de la red de amistad en $t 0$ y $t 1$

\begin{tabular}{|l|c|c|}
\hline & $t 0$ & $t 1$ \\
\hline Rango medio & 0,79 & 11,68 \\
Rango de entrada & $0-7$ & $2-27$ \\
Varianza del rango de entrada & 1,73 & 5,56 \\
Rango de entrada & $0-7$ & $0-35$ \\
Varianza del rango de entrada & 1,67 & 7,61 \\
Densidad & 0,020 & 0,148 \\
Reciprocidad & 0,992 & 0,896 \\
Transitividad & 0,00071 & 0,02438 \\
\hline
\end{tabular}

Cuatro meses más tarde la situación era ya muy diferente. El número medio de amigos había aumentado hasta casi 12 personas, lo que representa una cifra elevada si se la compara con otras redes de amistad de estudiantes de características similares (ver van de Bunt 1999). Las relaciones emitidas se situaban entre 0 y 35 , y las relaciones recibidas entre 2 y 27 . La densidad seguía siendo relativamente baja (es raro que redes de relaciones personales tan grandes tengan densidades elevadas) aunque siete veces mayor. La transitividad era baja también, pero menos que antes. Con una sociabilidad mayor y más difusa resulta más fácil que existan desacuerdos u olvidos cuando se habla de amistad mutua. 


\subsection{Factores de evolución de la red de amistad de $t 0$ a $t 1$}

Se presentan a continuación los factores que intervinieron en la evolución de la red de amistad entre estudiantes Erasmus entre $t 0$ y $t 1$ gracias a SIENA. Para analizar la evolución de la red se proponen algunas hipótesis que son sometidas a prueba para ilustrar el modo de proceder.

En un primer modelo se podría suponer que la evolución de la red de amistad se debe, en parte, a efectos estructurales endógenos al funcionamiento de la red. El primer modelo incluye por lo tanto los efectos estructurales de densidad (es indispensable incluirlo como variable de control), de reciprocidad (la idea de que es más probable escoger a aquellos que nos escogen) y de transitividad (los amigos de mis amigos devienen mis amigos) (ver la Tabla 2). Dado que los tres efectos son significativos, se dejan en el modelo y se incluyen 2-3 nuevas variables.

Tabla 2

Modelo con efectos estructurales

\begin{tabular}{|l|l|c|c|r|}
\hline \multicolumn{1}{|c|}{ Efecto } & Tipo & Parámetro & Desviación típica & $t$ \\
\hline Velocidad & Velocidad & 10,884 & 0,331 & - \\
Densidad & Estructural & $-1,40$ & 0,543 & $-2,59$ \\
Reciprocidad & Estructural & 2,769 & 0,560 & 4,94 \\
Transitividad & Estructural & 1,068 & 0,215 & 4,96 \\
\hline
\end{tabular}

El segundo modelo añade tres variables diádicas a las variables estructurales ya incluidas. Dichas variables son diádicas puesto que su valor depende de la combinación de las características de los dos actores implicados. Su distribución no puede ser expresada sino mediante una matriz. Por ejemplo, imagínese que el actor A y B son franceses y el actor C y D son españoles. Los pares A y B, por una parte, y C y D, tienen la misma nacionalidad, pero los pares A y C, A y D, B y C y B y D tienen nacionalidades diferentes. Se puede expresar esta relación mediante una matriz en la que el valor 1 simboliza la similitud de los actores respecto a la característica dada, aquí la nacionalidad, y 0 la diferencia respecto a esta característica.

$\begin{array}{lllll} & \text { A } & \text { B } & \text { C } & \text { D } \\ \text { A } & 1 & 1 & 0 & 0 \\ \text { B } & 1 & 1 & 0 & 0 \\ \text { C } & 0 & 0 & 1 & 1 \\ \text { D } & 0 & 0 & 1 & 1\end{array}$

Concretamente las variables diádicas que se han incluido en el modelo son: la estructura de oportunidades para conocer a alguien ligada a la proximidad geo- 
gráfica del lugar de residencia (es mas probable devenir amigo de alguien que vive cerca), la similitud de sexo (es más probable ser amigo de alguien de mismo sexo que de alguien de sexo diferente) y la similitud nacional (es más probable ser amigo de alguien de igual nacionalidad que de alguien de nacionalidad distinta).

En este punto se constata que la proximidad de lugar de residencia así como la similitud respecto a la nacionalidad tienen un papel en la evolución de la red (ver la Tabla 3). Sin embargo, de forma diferente a la mayoría de las poblaciones en que se han estudiado las relaciones de amistad, incluidos los estudiantes de edades similares, no se encuentran efectos de homofilia respecto al sexo. Puesto que no es significativa, esta variable es eliminada del modelo.

Tabla 3

Modelo con efectos estructurales y diádicos

\begin{tabular}{|l|l|c|c|r|}
\hline \multicolumn{1}{|c|}{ Efecto } & \multicolumn{1}{|c|}{ Tipo } & Parámetro & Desviación típica & \multicolumn{1}{c|}{$t$} \\
\hline Velocidad & Velocidad & 10,939 & 0,316 & - \\
Densidad & Estructural & $-1,541$ & 0,603 & $-2,55$ \\
Reciprocidad & Estructural & 2,280 & 0,468 & 4,87 \\
Transitividad & Estructural & 0,984 & 0,168 & 5,86 \\
Sim. Sexo & Diádico & $-0,093$ & 0,171 & $-0,54$ \\
Sim. Nacionalidad & Diádico & 1,192 & 0,183 & 6,51 \\
Sim. Residencia & Diádico & 0,793 & 0,104 & 7,62 \\
\hline
\end{tabular}

En el tercer modelo, se trata de someter a prueba efectos ligados a las características de los actores al igual que una variable a propósito de interacciones. Se constata en la figura 3 que los estudiantes británicos parecen tener menos amigos que los demás, así pues, someteremos a prueba la actividad (elecciones emitidas) de los británicos. Se constata también que los italianos se encuentran en el centro de una subred bastante dense, se puede poner a prueba entonces la popularidad (elecciones recibidas) de los italianos ${ }^{42}$.

Como variable de interacción se somete a prueba la reciprocidad según la similitud nacional. Se trata de ver si las relaciones de amistad entre personas de misma nacional tienden a ser más recíprocas que las relaciones de amistad entre personas de nacionalidad distinta.

Se constata (véase la Tabla 4) que los británicos son significativamente poco activos en el establecimiento de relaciones en la red, por otro lado los italianos son significativamente más populares que los demás.

Respecto a la reciprocidad según la nacionalidad, encontramos de nuevo el efecto inverso de lo que se hubiese podido esperar: cuando personas de nacio-

${ }^{42}$ Estos efectos no son necesariamente los más importantes para la constitución de esta red, su elección en este caso ha sido realizada con el mero objetivo de ilustrar las posibilidades de SIENA, no de explicar concretamente la evolución de esta red. Para resultados más precisos ver de Federico (2003). 
Tabla 4

Modelo con efectos estructurales, diádicos y atributos de los actores

\begin{tabular}{|l|l|r|r|r|}
\hline \multicolumn{1}{|c|}{ Efecto } & Tipo & Parámetro & $\begin{array}{c}\text { Desviación } \\
\text { típica }\end{array}$ & $t$ \\
\hline Velocidad & Velocidad & 12,535 & 0,323 & - \\
Densidad & Estructural & $-1,392$ & 0,578 & $-2,41$ \\
Reciprocidad & Estructural & 2,416 & 0,401 & 6,02 \\
Transitividad & Estructural & 0,825 & 0,182 & 4,53 \\
Sim. Nacionalidad & Diádico & 1,588 & 0,253 & 6,27 \\
Sim. Residencia & Diádico & 0,699 & 0,099 & 7,06 \\
Actividad de los británicos & Actores & $-2,553$ & 0,446 & $-5,72$ \\
Popularidad de los italianos & Actores & 0,286 & 0,142 & 2,01 \\
Reciprocidad X Sim. nacionalidad & Interacción & $-2,377$ & 0,759 & $-3,13$ \\
\hline
\end{tabular}

nalidad diferente establecen relaciones de amistad (de entrada menos frecuentes) éstas tienden a ser más recíprocas, más fuertes. $\mathrm{Al}$ parecer nos encontramos frente a una preferencia por bienes escasos. Este efecto, sorprendente y particularmente interesante en esta red, hubiese sido difícil de encontrar fuera del marco de análisis de SIENA.

Finalmente, en el cuarto modelo, se sugiere añadir un efecto ligado a la función de velocidad y un efecto ligado a la función de dotación, por ejemplo, las mujeres cambian más velozmente de relaciones de amistad que los hombres y las relaciones recíprocas tienen más probabilidades de sobrevivir que las demás.

Se constata (ver la Tabla 5) que ninguna de dichas variables tiene un efecto significativo en el desarrollo de la red de amistad estudiada, por lo que se eliminan del modelo.

Tabla 5

Modelo con efectos estructurales, diádicos y atributos de los actores, función de velocidad y de dotación

\begin{tabular}{|l|l|r|r|r|}
\hline \multicolumn{1}{|c|}{ Efecto } & Tipo & Parámetro & $\begin{array}{c}\text { Desviación } \\
\text { típica }\end{array}$ & $t$ \\
\hline Velocidad & Velocidad & 12,535 & 0,323 & - \\
Densidad & Estructural & $-1,452$ & 0,553 & $-2,62$ \\
Reciprocidad & Estructural & 2,416 & 0,401 & 6,02 \\
Transitividad & Estructural & 0,825 & 0,182 & 4,53 \\
Sim. Nacionalidad & Diádico & 1,588 & 0,253 & 6,27 \\
Sim. Residencia & Diádico & 0,699 & 0,099 & 7,06 \\
Actividad de los británicos & Actores & $-2,553$ & 0,446 & $-5,72$ \\
Popularidad de los italianos & Actores & 0,286 & 0,142 & 2,01 \\
Reciprocidad X Sim. nacionalidad & Interacción & $-2,377$ & 0,759 & $-3,13$ \\
Velocidad según el sexo & Velocidad & $-0,148$ & 0,086 & $-1,72$ \\
Dotación según la reciprocidad & Dotación & 0,001 & 0,128 & 0,01 \\
\hline
\end{tabular}


A modo de resumen se podría decir que la rede de amistad de los estudiantes Erasmus en Lille en 1995 se desarrolló a partir de un pequeño número de mecanismos bastante clásicos: 1) los amigos viven cerca, 2) se escoge como amigo a aquel que nos escoge como tal, 3) los amigos de mis amigos son mis amigos.

Además se han descubierto otros efectos originales: 1) Mientras que los estudios sobre la amistad muestran habitualmente la importancia de la homofilia relativa al sexo, ésta no contribuye a la formación de esta red de amistad. Se trata éste de un resultado específico a esta población. Se pueden concebir dos interpretaciones posibles y compatibles para explicar este fenómeno. Una posibilidad es que la estancia en el extranjero haya tenido un efecto liberador: las redes que habitualmente ejercen el control social sobre los roles ligados al género (como por ejemplo la familia o la pareja) no están presentes lo que permite la creación indistinta de relaciones homófilas u heterófilas. Otra posibilidad es que las personas estén cognitivamente limitadas en el número de criterios de similitud que pueden tener en cuenta a la hora de crear relaciones de amistad. Dado que se trata de una población internacional, el criterio de similitud que cobra más importancia es el de ser extranjero y después el de la nacionalidad, sería entonces cognitivamente exigente - y tal vez incluso difícil ene un contexto de elección restringida- para los individuos añadir también un criterio de homofilia respecto al sexo.

2) Otro resultado particularmente interesante es que las relaciones de amistad con personas de nacionalidad diferente sean más a menudo relaciones recíprocas. Las relaciones creadas con personas de distintos orígenes, a priori relaciones menos frecuentes, obtienen un estatus de reciprocidad más frecuentemente. Esto parece indicar una valorización particular de estos lazos escasos que poseen un valor añadido ligado a la diferencia de orígenes ${ }^{43}$.

3) Finalmente se ha podido constatar la existencia de diferencias en los modelos nacionales de sociabilidad teniendo como consecuencia comportamientos diferenciados por nacionalidades. De acuerdo con las investigaciones de Fischer (1982b) en que se comparaban estadounidenses y británicos, éstos últimos se muestran menos proclives a crear relaciones de amistad. Por otra parte, los italianos parecen ser preferidos como amigos respecto a otras nacionalidades.

\section{CONCLUSIÓN}

En este artículo se ha dado cuenta de los importantes desarrollos que han tenido lugar en los últimos 20 años en el campo de los modelos estadísticos de análisis de redes sociales en que dichas redes se consideran la variable dependiente a explicar a partir del comportamiento de los actores (ver la Tabla 6). Es-

$43 \mathrm{Y}$ de hecho se trata de un efecto que se mantiene a lo largo del tiempo. Al año de regresar del intercambio las relaciones transnacionales son significativamente mantenidas, mientras que aquellas con personas de igual nacionalidad desparecen con mayor facilidad (de Federico 2003a).

EMPIRIA. Revista de Metodología de Ciencias Sociales. N. ${ }^{\circ}$ 10, julio-diciembre, 2005, pp. 151-181. 
tos modelos han permitido profundizar el punto de vista propiamente «estructural» sobre las redes sociales, en el sentido «intencional» de la palabra según Boudon (1968, p. 35) que permite «subrayar que un método tiene como efecto describir un objeto en tanto que sistema».

Tabla 6

Modelos estadísticos para las redes sociales totales

\begin{tabular}{|l|l|l|l|l|}
\hline Modelo & \multicolumn{1}{|c|}{ Efectos } & Díadas & \multicolumn{1}{c|}{ Tríadas } & Dinámico \\
\hline$p 1$ & Endógenos & $\mathrm{Si}$ & $\mathrm{No}$ & No \\
$p 2$ & Endógenos y exógenos & $\mathrm{Si}$ & $\mathrm{No}$ & No \\
$p^{*}$ & Endógenos y exógenos & $\mathrm{Si}$ & Todos los tripletes & $\mathrm{Si}$ \\
SIENA & Endógenos y exógenos & $\mathrm{Si}$ & Lista de efectos en evolución & $\mathrm{Si}$ \\
\hline
\end{tabular}

El paso a los modelos de análisis dinámicos de los que SIENA y $p^{*}$ forman parte ${ }^{44}$ ha sido de gran importancia dado que dicha contribución metodológica es crucial para dar cuenta empíricamente de las teorías genéticas a propósito de las estructuras de las redes sociales totales. Permiten dar cuenta del conjunto de principios que gobiernan el desarrollo y la reproducción de una red social y por lo tanto definir la estructura de una red en esos términos. En lugar de enfatizar la descripción de la totalidad de las relaciones, se vuelve posible examinar los arreglos típicos de las relaciones, y sobretodo de la reproducción de dichos arreglos como resultado de la decisión de los actores de establecer (mantener o romper) una relación teniendo en cuenta las relaciones preexistentes.

En este punto otro comentario se vuelve importante dado que, paradójicamente, mientras los modelos estadísticos para analizar las redes sociales totales alcanzan la cima de la complejidad teórica y técnica, terminan por converger con proposiciones realizadas con anterioridad por las aproximaciones de análisis de redes personales (ver Ferrand 1997) por medio de encuestas representativas. Tal como lo expresa Ferrand (2002) el análisis de redes sociales totales está evolucionando, utilizando la distinción realizada por Claude Levi-Strauss, de una aproximación «mecánica» a una aproximación «estadística». La aproximación mecánica toma en cuenta los datos exhaustivamente completos como la verda-

44 Aunque en principio $p^{*}$ no fue condebido como un modelo de análisis longitudinal de redes, existe actualmente una versión dinámica (Robins et Pattison 2001). La diferencia teórica entre las dos concieme la orientación hacia el actor en SIENA, para relaciones de carácter más voluntario, y la orientación hacia la relación en $p^{*}$, que sirve para redes con un mayor grado de constreñimiento. De un punto de vista técnico, la principal diferencia técnica entre SIENA y la versión dinámica de $p^{*}$ es que el primer modelo aplica la idea de que existen pequeños cambios consecutivos en las relaciones que no son observados entre los momentos de observación de la red en $t 0$ y $t 1$, mientras que el segundo supone un cambio «de un solo paso", como si todo cambiase de golpe entre $t 0$ y $t$. Por otra parte, respecto a los procedimientos de aproximación de los parámetros Robins y Pattison admiten que la propuesta por SIENA es superior a la de $p^{*}$. 
dera expresión de un orden social prescrito mientras que la perspectiva estadística considera los datos como una expresión aproximativa de un orden social fundado sobre preferencias individuales limitadas por reglas proscriptivas.

Así pues la descripción de las propiedades de una red total por medio del recuento de tríadas y la evaluación estadística de su distribución (como lo hace $p^{*}$ ) abren nuevas posibilidades a la formalización de las estructuras de redes por medio de distribuciones estadísticas diferenciadas de sub-estructuras típicas. Una vez familiarizados con tales descripciones estaremos de acuerdo en que a) se puede pensar en las estructuras como en modelos probabilistas, b) que las proporciones de diferentes tipos de redes personales o de las subestructuras elementales típicas en una población halladas mediante muestras aleatorias proveen indicadores empíricos suficientes sobre los modelos de las estructuras relacionales subyacentes y desconocidos de los sistemas que nos interesan (Ferrand 1997, 2002, Spreen 1999). Más allá de la simple descripción, la aproximación genética para dar cuenta de los principios motores de a dinámica de redes sociales también ha sido puesto a prueba de forma pertinente en aproximaciones de redes personales (por ejemplo Ferrand 1997, Ferrand et al. 1999).

La aproximación a privilegiar entonces entre el análisis de redes personales o el de redes totales dependerá de las siguientes cuestiones a) ¿en qué medida las relaciones que se estudian están circunscritas a conjuntos con límites claros y pertinentes o acaso se trata de redes potencialmente infinitas? En el primer caso una aproximación en términos de redes totales es totalmente pertinente y más rica, en el segundo caso tiene más sentido una aproximación mediante redes personales. B) ¿Cuál es la extensión pertinente de la red alrededor del actor para explicar los cambios de relaciones que se producen en su entorno? Si se admite que, para las relaciones de carácter más bien voluntario el actor controla su red, decide establecer (mantener o romper) sus relaciones, una extensión relativamente limitada (por ejemplo una distancia 2) puede ser suficiente, incluso más pertinente teóricamente, dadas las limitaciones cognitivas de los actores en lo que respecta a las relaciones indirectas en las redes. En ese caso una aproximación en términos de redes personales puede ser suficiente para dar cuenta de la amplitud pertinente en juego para la dinámica de la red.

En cambio, para relaciones de carácter involuntario, o si se admite que incluso en el caso de relaciones voluntarias, los actores no controlan completamente sus redes y son sometidos a las consecuencias de las acciones de las relaciones indirectas (lo que puede ser particularmente el caso en el caso de conflictos, tal y como lo muestran Lorrain y White 1971 o Pizarro 2004) incluso más allá de lo que son conscientes, entonces la amplitud pertinente puede ser más amplia. Así pues las aproximaciones en términos de redes personales difícilmente pueden dar cuenta de efectos estructurales tales como las ventajas que pueden obtener actores en posiciones intermediarias entre partes de la red global no ligadas por otra parte (lo que se llaman «puentes« o «agujeros estructurales»). Allí donde los efectos estructurales son importantes la aproximación mediante redes totales sería preferible. 


\section{BIBLIOGRAFÍA}

Allan, G. H. (1979): A sociology of friendship and kinship. London, George Allen and Unwin.

- (1989): Friendship: Developping a social perspective. London, Harversten Neatsheaf.

BIDART, C. (1991): «L'amitié, les amis, leur histoire», Sociétés contemporaines, n. ${ }^{\circ} 5$.

- (1993): Les semblables, les amis et les autres: sociabilité et amitié, Thèse de doctorat, Marseille EHESS, 1993.

Bloch, F. et Buisson, M. (1991): «Du don à la dette: la construction du lien social familial», Revue du MAUSS, 11:54-71.

BoudON, R. (1968): A quoi sert la notion de «structure»?, Gallimard, París.

- (1984): La place du désordre : critique des théories du changement social, Sociologies, PUF, París.

Bunt, G. VAn DE (1999): Friends by choice. Amsterdam Thesis Publishers ICS series.

BURT R. S. (1992): Strucural holes. Cambridge, Harvard University Press.

CuCó I Giner, J. (1995): La amistad. Perspectiva antropológica. Icaria. Institut Català d'Antropologia.

DEGENNE, A. y FORSÉ, M. (1994): Les réseaux sociaux: une analyse structurale en sociologie. París, A. Colin.

DuIJN, M. A. J. vAN (1995): «Estimation of a random effects model for directed graphes». En: T. A. B. Snijders (Ed.) SSS'95 Symposium Statistische Software, nr. 7. Toeval zit overal: programmatuur voor random coeficient modellen (113-131). Groningen: ProGAMMA.

DuIJN, M. A. J. VAN; SNIJDERS, T. A. B. and ZiJLSTRA, B. H. (2004): «p2: a random effects model with covariates for directed graphs». Statistica Neerlandica, 58, pp. 234254.

Duijn, M. A. J. van; Zeggelink, E.; Huisman, M.; Stokman, F. N.; Wasseur, F. W. (2003): «Evolution of sociology freshmen into a friendship network». Journal of Mathematical Sociology, 27:153-191.

FEDERICO, A. DE (2003a): Réseaux d'identification à l'Europe. Amitiés et identités d'étudiants Européens. Tesis doctoral Université des Sciences et Technologies de Lille 1 (Francia) y Universidad Pública de Navarra.

- (2003b): «La dinámica de las redes de amistad. La elección de amigos en el programa Erasmus». REDES. Revista hispana para el análisis de redes sociales. Vol. 4, 2003.

- (2004): «L'analyse longitudinale de réseaux sociaux totaux avec SIENA. Méthode, discussion et application». Bulletin de Méthodologie Sociologique, 84:5-39.

FELD, S. L. (1997): «Structural embeddedness and stability of interpersonal relations». Social networks, 19(1):91-95.

FERRAND, A. (1993): L'Analyse des réseaux personnels. Habilitation à diriger des recherches en sciences sociales et humaines auprès de l'Université de Lille.

- (1997): «La structure des systèmes de relations» L'Année Sociologique, 1997. 47(1):37-54.

- (2002): «Las comunidades locales como estructuras meso». REDES. Revista Hispana para el análisis de redes sociales, 3(4).

FERrAND, A. y SNIJDERS, T. (1997): «Social networks and normative tensions». In Van Campenhoudt, L., Cohen, M., Guizzardi, G., Hauser, D, (eds.) Sexual interactions 
and HIV risk : new conceptual perspectives in European research, London, Taylor \& Francis, 6-21.

FERRAND, A.; MOUNIER, L. y DEGENNE, A. (1999): «The diversity of personal networks in France ; social stratification and relational structures». In Wellman, B. (ed.) : Networks in the global village, pp. 185-224. Westview Press. Boulder.

FISCHER C. S. (1982): «What do we mean by friends? An inductive study». Social Networks, n. $^{\circ} 3$.

FLAP, H. y VOLKER, B. (2002): «Occupational community and solidarity at work» presentado en la Second European Thematic Conference for Network Analysts. «Lilnet. Micro-macro relations: advances in the contribution of structural analysis», Lille, 3031 mayo 2002.

FRANK, O. (1991): «Statistical análisis of change in networks». Statistica Neerlandica, 45:283-293.

FRANK, O. y STRAUSS, D. (1986): «Markov graphs». Journal of the American Statistical Association, 81:832-842.

Godbout, J. y CharbonneaU, J. (1993): «La dette positive dans le lien familial». Revue $d u$ MAUSS, «Ce que donner veut dire», 235-256.

GRANOVETTER, M. S. (1973) « The strength of week ties " American Journal of Socio$\log y, 81: 1287-1303$.

HALLINAN, M. T. (1979): «The process of friendship formation», Social Netwoks, 1:193-210.

Holland, P. W. y LeINHARDT, S. (1976): «Local structures in social networks». En: D. Heise (ed.), Sociological methodology. San Francisco, Jossey Bass.

HOLLAND, P. W. y LEINHARDT, S. (1981): «An exponential family of probability distributions for directed graphs (with discussion)». Journal of the American Statistical Association, 76:33-65.

Huisman, M., y SNIJDERS, T. A. B. (2003): «Statistical analysis of longitudinal network data with changing composition». Sociological Methods \& Research, 32: 253-287.

LAZARSFELD, P. y MERTON, R. (1954): «Friendship as a social process», in Berger et al Freedom and control in modern society. Princeton, Van Nostrand.

LAZEGA, E. (2001): The Collegial Phenomenon: The Social Mechanisms of Cooperation Among Peers in a Corporate Law Partnership. Oxford, Oxford University Press.

LAZEGA, E. y vAN DUIJ, M. (1997): «Position in formal structure, personal characteristics and choices of advisors in a law firm: a logistic regression model for dyadic network data». Social Networks, 19:375-397.

LEENDERS, R. (1995): Structure and influence. Amsterdam, Thesis Publisher.

LORRAIN, F. y WHITE, H. (1971): «Structural equivalence of individuals in social networks», Journal of Mathematical Sociology, 1:49-80.

Mitchel., J. C., (ed.) (1969): Social Networks in Urban Situations. Manchester, Manchester University Press.

MolinA, J. L. (1995): «Análisis de redes y cultura organizativa: una propuesta metodológica». Revista española de investigaciones sociológicas, (71-72) pp. 249-263.

PAINE R. (1969): «In search of friendship». Man, vol. 4, pp. 505-524.

PIAGET, J. (1968): Le structuralisme. PUF Que sais je?.

PIZARRo, N. (2004): «Un nuevo enfoque sobre la equivalencia estructural : lugares y redes de lugares como herramientas para la teoría sociológica». REDES. Revista hispana para el análisis de redes sociales, $5(2)$.

REQUENA, F. (1994): Amigos y redes sociales. Centro de Investigaciones Sociológicas. Siglo XXI. Madrid. 
- (1996): Redes sociales y cuestionarios. Centro de Investigaciones Sociológicas. Cuadernos metodológicos. Siglo XXI. Madrid.

RoDrfGuez, J. A. (1995): Análisis estructural y de redes. Centro de Investigaciones Sociológicas. Cuadernos metodológicos. Siglo XXI. Madrid.

Robbins, H. y Monro, S. (1951): «A Stochastic Approximation Method». Ann. Math. Stat, 22:400-407.

RoBins, G. L., y PATtison, P. E. (2001): «Random graph models for temporal processes in social networks». Journal of Mathematical Sociology, 25, pp. 5-41.

SNIJDERS, T. A. B. (1996): «Stochastic Actor-Oriented Models for Network Change». Journal of Mathematical Sociology, 21(1-2):149-172.

SNIJDERS, T. A. B. (1998): "Methodological issues in studying effects of networks in organizations». Computational and Mathematical Organization Theory, 4, pp. 205-215.

- (2001): «The statistical Evaluation of Social Network Dynamics». in Sociological Methodology, edited by M. E. Sobel and M. P. Becker. Boston and London, Basil Blackwell, pp. 361-395.

- (2002): «Markov Chain Monte Carlo estimation of exponential random graph models". Journal of Social Structure. http://www.cmu.edu/joss/index.html

- (2005): «Models for Longitudinal Network Data». En: P. Carrington, J. Scott, \& S. Wasserman (Eds.), Models and methods in social network analysis. New York, Cambridge University Press.

SNIJDERS, T. A. B. DUIJ, M. VAN (1997): «Simulation for statistical inference in dynamic network models». In: Conte, R. Hegselmann, R. Terna, P. (Eds.) Simulating social phenomena, Berlin Springer. pp. 493-512.

SPREEN, M. (1999): Sampling Personal Network Structures: Statistical Inference in EgoGraphs. Thela Thesis. ICS Dissertation Series. University of Groningen.

WASSERMAN, S. (1980): «Analyzing social networks as stochastic protestes». Journal of the American Statistical Association, 75, pp. 280-294.

Wasserman, S. y Faust, K. (1994): Social Network Analysis: Methods and Applications. Cambridge, Cambridge University Press.

WASSERMAN, S. y IACOBUCCI (1988): «Sequential social network data». Psychometrika, 53:261-282.

WASSERMAN, S. y PATTISON, P. (1996): «Logit models and logistic regression for social networks: I. An introduction to Markov graphs and $p^{*}{ }_{\gg}$. Psychometrika, 61, pp. 401-425.

Wellman, B. (2000): «El análisis estructural: del método y la metáfora a la teoría y la sustancia». Política y sociedad, (33):11-40.

Wellman, B.; Carrington, P. J. y Hall, A. (1988): «Network as personal communities». En: Wellman, B. Berkowitz Social Structures: A Network Approach, Cambridge, University Press, pp. 130-84.

WEllmaN, B. y WORTLEY, S. (1990): «Different Strokes from different folks: Community ties and social support: Which ties provide what kinds of social support». American Journal of sociology, Novembre, 96(3):558-88.

ZEGGELINK, E. (1993): Strangers into friends. The evolution of friendship networks. Amsterdam, Thesis Publisher.

Zeggelink, E. P. H.; van Duijn, M.; Hiramatsu, H.; Stockman, F. N.; van Oosten, R. y WASSEUR, F. (1999): «Determinants of friendship formation: a comparative analysis of friendship formation among freshmen in Japan and the Netherlands». Sunbelt XIX International Conference on Social Networks, Charleston, 18-21 febrero 1999. 
Zeggelink, E. P. H.; Hiramatsu, H.; Stockman, F. N.; van Duin, M. y Wasseur, F. (1997): «Friendship formation over time among sociology students : a comparison between Japan and the Netherlands». XVIII Conferencia Internacional y V Conferencia Europea de Análisis de Redes Sociales. Sitges 27-31 Mayo 1997. 


\section{RESUMEN}

El objetivo de este artículo es explicar los principios de funcionamiento del modelo estadístico SIENA para el análisis longitudinal de redes sociales totales. En primer lugar se expone la especificidad de los modelos estadísticos para explicar la emergencia de las estructuras de las redes acompañada una breve historia de los principales modelos aparecidos para este propósito. Después se exponen los postulados en los que se basa el modelo SIENA y se discute su realismo teórico. A continuación se presentan las especificaciones del modelo y los efectos principales que se pueden estudiar con él. Terminamos con un ejemplo de aplicación del modelo a la evolución de una red de amistad internacional.

\section{PALABRAS CLAVE}

Análisis longitudinal, redes sociales, SIENA, redes transnacionales, sociología de la amistad.

\section{ABSTRACT}

This article explains the functional basis of the SIENA statistical model for the analysis of longitudinal total social networks. In the first part, we explain the specificity of statistical models for analyzing network structure and give a brief history of the major models proposed in the past which produced dynamic models such as SIENA. We then present the basis on which SIENA is constructed and we discuss the theoretical implications. Model specification follows with a presentation of the principal effects which can be studied with this model. We end with an example of application on a network of international friendships.

\section{KEY WORDS}

Longitudinal analysis, social networks, SIENA, transnational networks, sociology of friendship. 